\title{
DISPARITY IN DIAGNOSIS OF GESTATIONAL DIABETES MELLITUS USING 75g AND 100g GLUCOSE LOAD TESTS AMONG ANTE-NATAL ATTENDEES AT MADONNA UNIVERSITY TEACHING HOSPITAL, ELELE, RIVERS STATE
}

\author{
${ }^{1}$ C.G.ORLUWENE, \\ B.Med. Sci; MBBS; FMCPath \\ ${ }^{2}$ J.D. OJULE \\ MBBS; FWACS
}

\begin{abstract}
1. Department of Chemical Pathology, University of Port Harcourt Teaching Hospital, Port Harcourt, Rivers State

2. Department of Obstetrics and Gynaecology, University of Port Harcourt Teaching Hospital, Port Harcourt Rivers State
\end{abstract}

\begin{abstract}
Several cases of Gestational diabetes mellitus (GDM) are seen in our working environment and this condition can have substantial impact on fetal growth, birth weight and morbidity. Standard recommendations for GDM testing prescribe the use of either a 3-hour, $100 \mathrm{~g}$ glucose load (100g) or a 2-hour $75 \mathrm{~g}$ glucose load $(75 \mathrm{~g})$. We investigated the comparability of the $75 \mathrm{~g}$ and the $100 \mathrm{~g}$ tests in the diagnosis of GDM in our environment. From February, 2007 to January 2010, we performed the GDM testing using a 75g glucose load on 956 consecutive Nigerian non-obese and non-diabetic pregnant women who attended the antenatal clinic of the Madonna University Teaching Hospital, Elele, Rivers State. This testing was carried out during two periods of pregnancy: early (16-24weeks) and late (26-34weeks). All women with 1-hour plasma glucose above $7.2 \mathrm{mmol} / \mathrm{L}$ in the $75 \mathrm{~g}$ test were retested using the $100 \mathrm{~g}$ glucose load within a week. Gestational diabetes mellitus (GDM) was diagnosed (during the 16-24weeks) in 46 out of 269 women with the $100 \mathrm{~g}$ and 18 out of 269 with the $75 \mathrm{~g}$ load (12 concordant); the $k$ index was 0.22. At 26-34 weeks of pregnancy, 388 out of 950 women (40.8\%) underwent both tests. GDM was diagnosed in 65 of 388 women with $100 \mathrm{~g}$ load and in 29 of 388 women with the $75 \mathrm{~g}$ load (14 concordant); the $k$ index was 0.19.Among women with positive GDM in both early and late periods of pregnancy, there was only weak diagnostic agreement between results determined with $75 \mathrm{~g}$ and $100 \mathrm{~g}$ glucose loads.
\end{abstract}

KEYWORDS: Gestational-Diabetes-Mellitus, Diagnosis, Ante-natal-attendees, 75g/100g-glucose-load-tests, Elele-Rivers State.

\section{INTRODUCTION}

Gestational diabetes mellitus (GDM) is a common disturbance that has a substantial impact on pregnancy outcomes such as fetal growth, birth weight and morbidity. In the Nigerian environment, as a result of Westernization (a move from the primitive African culture, especially in terms of diet and general life style to the Western pattern of diet and general lifestyle) a number of the disease conditions which were hitherto alien to our culture have crept in and some like diabetes mellitus and GDM are assuming epidemic proportion. For this reason, most pregnant women in developed and developing countries undergo GDM testing as part of routine ante-natal care. The clinical practice recommendations issued by the American Diabetes Association (ADA) in 2003 [1] state that GDM is diagnosed on the basis of oral glucose tolerance test (OGTT). The OGTT in current use in our medical practice comprises either a 3-hour, 100g glucose load (100g) [2] at fasting and 1, 2 and 3 hours after the glucose load, or a 2-hour, 75g glucose load (75g) [3,4], with the same criteria at fasting and 1 and 2 hours after glucose load. This recommendation derives from the conclusions of the ADA Fourth International Workshop Conference on Gestational Diabetes Mellitus, held in March, 1997, where it was first suggested that both tests, at the same cutoff values, could be used to diagnose GDM [3]. Despite their supposed equivalence, the 2 tests clearly have relevant differences and have not been compared thus far as to their usefulness for identifying women with GDM in the same population. The aim of this study was to compare the performance of the $75 \mathrm{~g}$ and $100 \mathrm{~g}$ tests in pregnant women with possible or diagnosed GDM according to the $75 \mathrm{~g}$ test in our Rivers State, Nigerian environment and among our own immediate population. 


\section{SUBJECTS AND METHODS}

From February 2007 to January 2010, 956 consecutive Nigerian non-obese and non-diabetic pregnant women with singleton pregnancy attending the ante-natal clinic of the Department of Obstetrics and Gynaecology of the Madonna University Teaching Hospital, Elele, Rivers State, Nigeria were tested for GDM with a 75g OGTT performed during 2 period of pregnancy: early (16-24weeks) and late (26-34weeks). Details of maternal demographic and anthropometric characteristics were obtained from all women at the time of first $75 \mathrm{~g}$ test (16-24 weeks). Gestational age had been determined by first trimester dating scan. Within the early pregnancy period (16-24 weeks), all pregnant women underwent a $75 \mathrm{~g}$ test at 16-24 weeks of pregnancy. To identify and treat women with gestational diabetes as soon as possible, as described [4], we chose to begin screening for GDM at a time different from the ADA recommendation of 24-28 weeks (which was largely for the Caucasian population). We collected venous blood specimens into fluoride oxalate tubes and measured plasma glucose at fasting and 60 and $120 \mathrm{~min}$ after the $75 \mathrm{~g}$ load. We assumed that there were few GDM cases among the women with a 1-hour result $<7.2 \mathrm{mmol} / \mathrm{L}$ on the $75 \mathrm{~g}$ test; accordingly, for all women with a plasma glucose concentration $\geq 7.2 \mathrm{mmol} / \mathrm{L}$ after 1 -hour, we performed a $100 \mathrm{~g}$ test within 1 week. Carpenter and Coustan [2] diagnostic criteria were used for the $100 \mathrm{~g}$ interpretation. Diagnosis of GDM was made when 2 or more venous plasma glucose concentrations met or exceeded the following concentrations: fasting concentration, $5.3 \mathrm{mmol} / \mathrm{L}$; 1 -hour results, $10 \mathrm{mmol} / \mathrm{L}$; 2-hour, $8.6 \mathrm{mmol} / \mathrm{L}$; and 3-hour $7.8 \mathrm{mmol} / \mathrm{L}$. to interpret the results of the $75 \mathrm{~g}$ test, we used the same criteria without the 3 -hour value, as recommended by the Fourth International Workshop Conference on Gestational Diabetes Mellitus Recommendations. Our study design is comparable to the study design adopted by Pettitt et al. [5], in which $75 \mathrm{~g}$ glucose load was administered to nonfasting women during pregnancy for the diagnosis of impaired glucose tolerance and diabetes. They tested women with 1-hour plasma glucose of $\geq 7.8 \mathrm{mmol} / \mathrm{L}$ with a $100 \mathrm{~g}$ load after an overnight fast. Because the glucose load makes little difference in the glucose concentration at 1-hour in persons with typical glucose tolerance [5], this cutoff point is comparable to a glucose concentration of $7.8 \mathrm{mmol} / \mathrm{L}$ after a $50 \mathrm{~g} \mathrm{load}$, the concentration above which the $100 \mathrm{~g}$ test is recommended according to National Diabetes Data Group criteria.

In late pregnancy (26-34weeks), all women without GDM according to $75 \mathrm{~g}$ or $100 \mathrm{~g}$ test at $16-24$ weeks gestation were re-tested at 26-34 weeks with a $75 \mathrm{~g}$ glucose load. Assuming that very few GDM cases would be found among the women with a 1 -hour result of $<7.2 \mathrm{mmol} / \mathrm{L}$ on the $75 \mathrm{~g}$ test, we performed a $100 \mathrm{~g}$ test within 1 week only in women with a plasma glucose concentration $>7.2 \mathrm{mmol} / \mathrm{L}$ after 1 -hour for the $75 \mathrm{~g}$ test. We performed data analysis on results obtained from women who underwent both $75 \mathrm{~g}$ and $100 \mathrm{~g}$ tests. Six (6) out of the 956 women $(0.01 \%)$ could not continue the GDM screening/diagnosis programme. We measured plasma glucose with an automated enzymatic assay performed using Dimensions Expand Plus (Siemens). The study was approved by the Ethical Committee of the Institution. The participants gave informed consent.

\section{STATISTICAL METHODS}

We used the Cohen $\mathrm{k}$ index to assess the overall reliability of the 2 glucose load tests. Values for $\mathrm{k}$ ranged from 0 to 1.00 , with higher values indicating their reliability. A $\mathrm{k}$ index of $0-0.2$ suggested weak agreement, 0.2-0.4 fair agreement, 0.4-0.8 good agreement, and 0.8-1.0 perfect agreement. 0 values suggested total disagreement [6]. We also performed analysis with a McNemar test [7] to compare the performance of the $75 \mathrm{~g}$ and $100 \mathrm{~g}$ glucose loads in the detection of GDM. We considered $\mathrm{P}<0.05$ to be statistically significant. We used the Wilcoxon rank-sum test to assess the significance of continuous data and calculated Spearman correlation coefficient for paired responses at each testing interval of the oral glucose load. Statistical analysis was performed with the statistical package for the social sciences for windows, version 6 (SPSS 6.0).

\section{RESULTS}

Maternal Demographic and anthropometric characteristics of the women who underwent both the $75 \mathrm{~g}$ and the $100 \mathrm{~g}$ tests in early and late periods of pregnancy are shown in Table 1 and 2 respectively.During the early period of gestation (16-24weeks), 269 of 950 women (28.3\%) underwent both the $75 \mathrm{~g}$ and the $100 \mathrm{~g}$ tests. At this stage, the $100 \mathrm{~g}$ test was diagnostic for GDM in 46 out of the 269 women (17.1\%), the $75 \mathrm{~g}$ test was diagnostic for GDM in 18 out of 269 women $(6.7 \%)$ and both tests in 12 women. The $\mathrm{k}$ index was 0.22 . The mean glucose load values $(\mathrm{mmol} / \mathrm{L})$ at each time point for the 269 women during the early gestation period are shown in Table 3. Mean glucose concentrations differed significantly between the 2 tests at the 2-hour time points but were not significantly higher in the $100 \mathrm{~g}$ test than the $75 \mathrm{~g}$ tests at the fasting and 1-hour time points.

A significant correlation between the glucose was found only at $60 \mathrm{~min}$. In the late gestation (26-34 weeks) period, 388 out of 950 women (40.8\%) underwent both the $75 \mathrm{~g}$ and $100 \mathrm{~g}$ tests (Table 4 ). At this stage, the $100 \mathrm{~g}$ tests was diagnostic for GDM in 65 out of 388 women (16.8\%), the $75 \mathrm{~g}$ test was diagnostic for GDM 
in 29 out of 388 women $(7.5 \%)$ and both tests in 14 women. The $\mathrm{k}$ index was 0.19 . The mean plasma glucose load values at each time point for the 388 women during the late periods of gestation are shown in Table 4. Mean plasma glucose concentrations differed significantly between the 2 tests at the 2-hour time point, and a significant correlation existed between the 2 tests for 1-hour and 2-hour values. The McNemar test results were highly significant $(\mathrm{P}<0.001)$ which may indicate that GDM diagnosis was more likely with the $100 \mathrm{~g}$ than the $75 \mathrm{~g}$ test, but in some cases, diagnosis was made by only the $75 \mathrm{~g}$ test. At the later time point, GDM was diagnosed in 16 women by the $75 \mathrm{~g}$ test but not in the $100 \mathrm{~g}$ test and in 52 by the $100 \mathrm{~g}$ test but not the $75 \mathrm{~g}$ test; the McNemar test results again were highly significant $(\mathrm{P}<0.001)$. Nevertheless, a substantial number of women (16) had positive results only for the $75 \mathrm{~g}$ test.

\section{DISCUSSION}

The Fourth international Workshop Conference on Gestational Diabetes Mellitus, in 1997 issued recommendations for the diagnosis of GDM that are accepted worldwide. It was suggested that the diagnosis of GDM can be made on the basis of an OGTT performed with either a 1-step or a 2-step strategy. The selected cutoff values for the 100g test [2] had been extrapolated from the 0' Sullivan and Mahan data and were originally intended to predict the likelihood of maternal overt diabetes later in life, rather than adverse pregnancy outcome and/or GDM-related perinatal morbidity [8] The same cutoff values were adopted for the $75 \mathrm{~g}$ and $100 \mathrm{~g}$ tests, but the $75 \mathrm{~g}$ test is considered positive when 2 or 3 values are abnormal instead of the 2 of 4 abnormal values required for a $100 \mathrm{~g}$ test [1]. The decision to sue the same cutoff values was based on previous studies $[5,9,10]$. To date, the $75 \mathrm{~g}$ glucose load in pregnancy has been used more than the traditional $100 \mathrm{~g}$ load in our study environment, probably because the $75 \mathrm{~g}$ test was developed to diagnose diabetes in non-pregnant persons, but this test has had little validation in pregnant women [1]. As Weiss et al. [11] have observed, generalized use of the 75g test recommended by the ADA has been impeded by the lack of data directly comparing the test with the $100 \mathrm{~g}$ test. Those studies that have applied both tests have done so to investigate the incidence of adverse pregnancy outcomes successfully predicted by each test $[5,10,12]$. The relationship between glucose concentration results from a $75 \mathrm{~g}$ test and the risk of abnormal neonatal anthropometric features has been reported in a previous investigation performed on 829 glucose tolerant pregnant women [4]. In that study, $75 \mathrm{~g}$ load glucose challenge test was used with a threshold of $7.5 \mathrm{mmol} / \mathrm{L}$; prompted by the observation that in glucose-tolerant women, there are no differences between 1-hour glucose values after a $50 \mathrm{~g}$ load and after a $75 \mathrm{~g}$ load. In this study, we also defined, at the 1-hour time point for the $75 \mathrm{~g}$ load, threshold glucose values above which there is an increased risk for abnormal neonatal anthropometric characteristics, interestingly, this association was observed at 16-24 weeks of pregnancy. Our results can be used as a single tests for the diagnosis of GDM.

The results of our study, performed on a sample of Nigerian women studied, suggested that when testing is performed according to ADA recommendations, only a weak agreement between the $75 \mathrm{~g}$ and $100 \mathrm{~g}$ test results occurs for women with possible or diagnosed GDM in the early stages of pregnancy. In the late period of pregnancy, our result shows a weak amount of agreement. Hence, we can state that the 2 test cannot be used interchangeably and cannot be assumed to share similar diagnostic characteristics. In addition, the prevalence of diagnosed GDM was lower with the 75g test in both early and late periods of pregnancy. Although the ADA suggests that values for the 2 tests are "similar" [1], this claim was not upheld by our study in which the 2-hour values were significantly different for the 2 tests, even when only the mean values obtained from our results were considered. These findings have also been reported for other studies, such as those conducted by Brustman et al. [13] and Weiss et al. [11]. Brustman et al. [13] compared the results of a 3-hour, 75g glucose load OGTT with those of a $100 \mathrm{~g}$ test in 32 pregnant women from high-risk ethnic groups. They found that the 1-, 2- and 3hour plasma glucose values for the $100 \mathrm{~g}$ test were significantly higher than

the comparable values for the $75 \mathrm{~g}$ test in women with normal glucose tolerance and with GDM. In addition, the prevalence of results diagnostic for GDM was found to be higher with the $100 \mathrm{~g}$ test. Weiss et al. [11] compared $75 \mathrm{~g}$ and $100 \mathrm{~g}$ glucose loads during a 2-hour OGTT in 30 women with GDM and 30 healthy pregnant women and found that in healthy women, plasma glucose concentrations at both 1- and 2-hour obtained after a $100 \mathrm{~g}$ load were significantly higher than those obtained after a $75 \mathrm{~g}$ load. Our results, obtained for a much larger sample population, are in agreement with those of these 2 studies. The previous results were confirmed by the results of the McNemar test, which indicate that the $100 \mathrm{~g}$ test is more powerful in detecting GDM, a finding that may be attributable to the extra time point, which gives an extra opportunity to cross the threshold, although in some women,

GDM was detected only by the less powerful $75 \mathrm{~g}$ test. Because we did not repeat the $75 \mathrm{~g}$ or the $100 \mathrm{~g}$ test for any of our study participants and because the 2 tests were not performed on the same day, but within a week of one another, it is possible that some of the variation revealed could be caused by day-to-day variability 
in testing or in glycemic response. To our knowledge, however, no previous studies have examined the reproducibility of either test, and those studies that have compared the 2 test have also done so within a 1-2 week interval. [11, 13, 14].

\section{CONCLUSION}

Among Nigerian women with possible GDM in both early and late gestation, there was only weak diagnostic agreement between results determined with $75 \mathrm{~g}$ and $100 \mathrm{~g}$ glucose loads. The $100 \mathrm{~g}$ glucose load appears to be more powerful in the diagnosis of GDM in the Nigerian population. Our study may represent a preliminary step in the diagnostic accuracy evaluation of the $75 \mathrm{~g}$ glucose load OGTT. Further studies are needed to establish the appropriate cutoff values for the use of the $75 \mathrm{~g}$ test in pregnancy.

Table 1: Demographic and Anthropometric characteristics of 269 Ante-natal attendees who performed both the $75 \mathrm{~g}$ and the $100 \mathrm{~g}$ tests in the period of gestation

\section{Number of subjects}

Age of subjects, years (SD)

Parity $\geq 2, \%$

Family history of diabetes, $\%$

Maternal Macrosomia ${ }^{+}, \%$

Previous Macrosomia ${ }^{+}, \%$

Maternal weight gain, $\mathrm{kg}$ (SD)

+ Macrosomia was defined as birth weight $\geq 4 \mathrm{~kg}$

\section{9}

$32.4(4.8)$

$89.0(33.2)$

$52(19.3)$

$21(7.8)$

$13(4.8)$

$11.4(3.1)$

Table 2: Demographic and Anthropometric characteristics of 388 ante-natal attendees who performed both $75 \mathrm{~g}$ and $100 \mathrm{~g}$ test in the late period of gestation

\section{Number of subjects}

Maternal age, years (SD)

Parity $\geq 2, \%$

Family history of diabetes, \%

Maternal Macrosomia, \%

Previous Macrosomia, \%

Maternal weight gain, $\mathrm{Kg}$ (SD)
388

$30.3(4.5)$

$162(41.8)$

$102(26.3)$

$38(9.8)$

23 (5.9)

$12.1(2.9)$ 
Table 3: Mean plasma glucose values $(\mathrm{mmol} / \mathrm{L})$ each time point in the early gestation period for the $75 \mathrm{~g}$ and $100 \mathrm{~g}$ tests

$\mathrm{n}=\mathbf{2 6 9}$

Test

Test interval

Fasting

1-hour

2-hour

3-hour

Test

$75 \mathrm{~g}$

$4.5(0.9)^{*}$

$8.8(1.7)$

$7.2(1.3)$

$7.9(1.7)$

0.018

$6.5(1.2)$

\section{Correlation Analysis}

$\mathbf{r}$

$\mathbf{P}$

$-0.57$

0.17

0.31

0.022

0.11

0.64

* Data are expressed as mean $(\mathrm{SD}) ; \mathrm{SD}=$ Standard deviation.

Table 4: Mean plasma glucose values $(\mathrm{mmol} / \mathrm{L})$ at each time point in the late gestation period for the $75 \mathrm{~g}$ and $100 \mathrm{~g}$ tests.

$\mathbf{n}=\mathbf{3 8 8}$

\section{Test}

\section{Test interval}

Fasting

1-hour

2-hour

3-hour

* Data are expressed as mean (SD).

\section{Correlation Analysis}

$\begin{array}{lllll}75 g & 100 g & P & \text { r } & \text { P }\end{array}$

$\begin{array}{lllll}4.3(0.6) * & 4.5(0.7) & -0.75 & 0.15 & -0.058 \\ 9.0(1.6) & 9.1(1.7) & -0.32 & 0.33 & 0.020 \\ 7.4(1.4) & 7.7(1.6) & 0.007 & 0.30 & 0.026\end{array}$

$6.6(1.5)$ 


\section{REFERENCES}

[1] Expert Committee on the Diagnosis and classification of Diabetes Mellitus. Report of the expert committee on the diagnosis and classification of diabetes mellitus. Diabetes care, 26 (Suppl 1), 2003; 5-20.

[2] Carpenter WM, Coustan DR. Criteria for screening tests for gestational diabetes. Am J Obstet Gynecol, 144, 1982; 768-773.

[3] Metzger BE, Coustan DR. Summary and recommendation of the Fourth International Workshop-Conference on Gestational Diabetes. Diabetes care, 21, 1998; B161-167.

[4] Mello G, Paretti E. Cioni R, Lucchetti R, Carignani L, Martini E, et al. The 75-gram glucose load in pregnancy: relation between glucose levels and anthropometric characteristics of infants born to women with normal glucose metabolism. Diabetes Care, 26, 2003; 1206-1210.

[5] Pettitt DJ, Benneth PH, Hanson RL, Narayan KMV, Knowler WC. Comparison of World Health Organization and National Diabetes Data Group procedures, Diabetes Care, 17, 1994; 1264-1268.

[6] Grant A, Mohide P. Screening and diagnostic test in antenatal care. In: Enkin M, Chalmers I, eds. Clinics in Developmental Medicine, Nos. 81/82. Effectiveness and satisfaction in Antenatal care. Vol. 1 London: Spastics International Medical Publications/Heinemann Medical 1982:22 - 59.

[7] Agresti A. Categorical Data Analysis. New York: John Wiley and Sons, 1990.

[8] O’Sullivan JB, Mahan CM. Criteria for the oral glucose tolerance test in pregnancy. Diabetes, 13, 1964; $278-285$.

[9] Sacks DA, Greenspoon JS, Abu-Fadil S, Henry HM, Wolde-Tsadik G, Yao JF. Toward universal criteria for gestational diabetes: the 75-gram glucose tolerance test in pregnancy. Am J Obstet Gynecol, 172, 1995; 607-614.

[10] Deerochanawong C, Putiyanum C, Wongsuryrat M, Serirat S, Jinayon P. Comparison of National Diabetes Data Group and World Health Organization criteria for detecting gestational diabetes mellitus. Diabetologia, 39, 1996; 1070-1073.

[11] Weiss PA, Haeusler M, Kainer F, Purstner P, Haas J. Toward universal screening for gestational diabetes: relationships between Seventy-five and one hundred gram glucose loads and between capillary and venous glucose concentrations. Am J Obstet Gynecol, 178, 1998; 830-835.

[12] Schmidt MI, Duncan BB, Reicheit AJ, Branchtein L, Matos MC, Coasta Forti A, et al. gestational diabetes mellitus diagnosed with a 2-h 75-g oral glucose tolerance test and adverse pregnancy outcomes. Diabetes care, 24, 2001; 1151-1155.

[13] Brustman LE, Gela BD, Moore M, Reilly KD, Langer O. Variations in oral glucose tolerance tests: the 100-versus 75-g controversy. J. Assoc Acad Minor Phys, 6, 1995; 70-72.

[14] Harlass FE, Brandy K, Read JA. Reproducibility of the oral glucose tolerance test in pregnancy. Am J Obstet Gynecol, 164, $1991 ; 564-568$. 